\begin{abstract}
"Mircea cel Batran" Naval Academy Scientific Bulletin, Volume XX - 2017 - Issue 1
The journal is indexed in: PROQUEST / DOAJ / Crossref / EBSCOhost / INDEX COPERNICUS / DRJI / OAJI I

JOURNAL INDEX I I2OR / SCIENCE LIBRARY INDEX / Google Scholar / Academic Keys/ ROAD Open Access I Academic Resources / Scientific Indexing Services / SCIPIO / JIFACTOR
\end{abstract}

\title{
WE CAN INTRODUCE THE NOTION OF OPTIMAL DESIGN IN RATES OF MACHINE?
}

\author{
Mihaela TUROF ${ }^{1}$ \\ ${ }^{1}$ Assistant Ph.D. Department of General Engineering Sciences, Naval Electromechanics Faculty, Constanta \\ Maritime University, mihaela_turof@yahoo.com
}

\begin{abstract}
Optimization is a process to decide on the best solution of two or more possible. In the field of machine optimization process consists of establishing a algorithms (design method) in which starts at tasks (force and moments exterior) that loads the song, select a group of materials that might be used (for that known resistance characteristics) and add restrictions (which limits certain solutions or use of certain materials). In addition, consider a function of purpose that must be maximized or minimized (for example: minimal use of materials, minimal cost price, high efficiency, durability, etc.). With this set of data, restrictions and functions of purpose creates a "operational model" that leads to "optimal solution" - optimized proper purpose.
\end{abstract}

Key words: process optimization, algorithm, mechanical design

\section{General considerations. (Introductory Elements)}

The study "classic" machine parts, requires theoretical approach what role and form constructive them, the materials used for their execution, the study of forces and moments exterior and the application of the calculation resistance for sizing, verification and calculation of deflections these pieces - called generic design stage.

The applicative (seminar, project, lab) - is the basis of solving problem practical simple or complex (project), in which the student becomes familiar with how relationships computing (set at the theoretical) are adapted and applied to a set several component parts.

In calculating practically sizing machine element is based on a request considered the main, following that for requests deemed "secondary" or other restrictions imposed (eg limitation of deformation, buckling) to make "Verification" by making a calculation to show whether those restrictions are observed.

If some of these restrictions "does not check" proceed to unjustified increase of size or replace the selected material from the beginning and is recalculated " from the beginning " or some stages, including" checking " successive until the restrictions are met.

Such a design method is, in some cases, laborious and irrational, as increasing dimensions must be done "step" small (not to exaggerate lead to excessive size, and even sometimes the problem is unsolvable).

Optimization is a process to decide on the best solution of two or more possible. In the field of machine optimization process consists of establishing a algorithms (design method) in which starts at tasks (force and moments exterior) that loads the song, select a group of materials that might be used (for that known resistance characteristics) and add restrictions (which limits

(c) 2017. This work is licensed under the Creative Commons Attribution-Noncommercial-Share Alike 4.0 License. certain solutions or use of certain materials). In addition, consider a function of purpose that must be maximized or minimized (eg minimal use of materials, minimal cost price, high efficiency, durability, etc.).

With this set of data, restrictions and functions of purpose creates a "operational model" that leads to "optimal solution" - optimized proper purpose.

\section{Example}

To dimension a straight bar of length $[[\mathrm{mm}]$, requested the axial center a force $\mathrm{N}[\mathrm{N}]$ so as to ensure an elongation $\Delta l \geq \delta_{\max }$ at a price of minimum cost, knowing that the price is proportional to the cross-sectional area $A\left[\mathrm{~mm}^{2}\right]$ and material quality (allowable resistance expressed by $\sigma_{a}[\mathrm{MPa}]$ and according to the relationship

$$
(\min ) P=\alpha A+\beta \sigma_{a}[l e i]
$$

as the best material available is allowable voltage tension $\sigma_{a M}[\mathrm{MPa}]$

\section{Classical method design}

It is considered the known relations of Strength of Materials

$A=\frac{F}{\sigma_{a}} \quad$ - restriction tension in crosssection

$\Delta l=\frac{F \cdot l}{E \cdot A} \geq \delta_{\max } \quad$ - restriction stiffness

$1^{\text {st }}$ Solution 
"Mircea cel Batran" Naval Academy Scientific Bulletin, Volume XX - 2017 - Issue 1

The journal is indexed in: PROQUEST / DOAJ / Crossref / EBSCOhost / INDEX COPERNICUS / DRJI / OAJI I JOURNAL INDEX / I2OR / SCIENCE LIBRARY INDEX / Google Scholar / Academic Keys/ ROAD Open Access I Academic Resources / Scientific Indexing Services / SCIPIO / JIFACTOR

Choose a material that has the strength admissible $\sigma_{a 1}$ and calculates the area $A_{1}=\frac{F}{\sigma_{a 1}}$ and then check if $\Delta l=\frac{F \cdot l}{E \cdot A_{1}} \geq \delta_{\max }$

If this condition do not check $\left(\Delta l<\delta_{\text {max }}\right)$ there are two ways of solving

1. It keeps rolling (cu $\sigma_{a 1}$ ) and increases $A_{1}$ the value range $A_{2}>A_{1}$, then check again if $\Delta l=\frac{F \cdot l}{E \cdot A_{2}} \geq \delta_{\max }$, and this process continues through successive enlargements until check $\Delta l \geq \delta_{\text {max }}$

2. Choosing a superior material (having resistance allowable $\sigma_{a 2}>\sigma_{a 1}$ ) it calculates the area $A_{2}=\frac{F}{\sigma_{a 2}}$, and then check the condition $\Delta l=\frac{F \cdot l}{E \cdot A}=\delta_{\max }$, and if you do not check, increases $A_{2}$ section and check and restriction $\Delta l \geq \delta_{\text {max }}$, repeating the steps enlarge

It is possible that any solution not check, even when using the material with the highest resistance permissible and the problem is declared incompatible (unsolvable). Observe that in this variant was not considered "price" designed product.

\section{$2^{\text {nd }}$ Solution}

$$
\text { In relationship } \Delta l=\frac{F \cdot l}{E \cdot A}=\delta_{\max },
$$

to replace $A=\frac{F}{\sigma_{a}}$,

result $\Delta l=\frac{F \cdot l}{E \cdot A}=\frac{F \cdot l}{E \frac{F}{\sigma_{a}}}<\delta_{\max }$ or

$$
\sigma_{a}=\frac{F \cdot E}{l}
$$

Then calculates $A=\frac{F}{\sigma_{a}}$ and then the

cost price $P=\alpha A+\beta \sigma_{a}$

Observe that, in this method was not material choice was not arbitrary, but was especially material from the beginning, one that has
$\sigma_{a}=\frac{F \cdot E}{l}$ and $\Delta l \geq \delta_{\max }$ provide, resulting the cost price.

\section{Operational method (optimal design) The condition $A=\frac{F}{\sigma_{a}}$ restiction is} imposed $A \geq \frac{F}{\sigma_{a}}$, which is considered the limit as a condition

$$
u_{1}=A \cdot \sigma_{a}-F \geq 0
$$

The condition $\Delta l=\frac{F \cdot l}{E \cdot A} \geq \delta_{\max }$ extract

$$
u_{2}=A-\frac{F \cdot l}{E \cdot \delta_{\max }} \leq 0
$$

Add condition

$$
u_{3}=\sigma_{a}-\sigma_{a M} \leq 0
$$

showing that there is no other material better than having $\sigma_{a M}$ (max)

$$
(\max ) P=\alpha A+\beta \sigma_{a}[\text { lei }]
$$

$$
\text { minim cost price condition }
$$

The conditions (1), (2), (3), (4) must be met simultaneously, so the system consists of these equations must be compatible.

To consider all possible solutions must be graphically represents these conditions, the system of axes

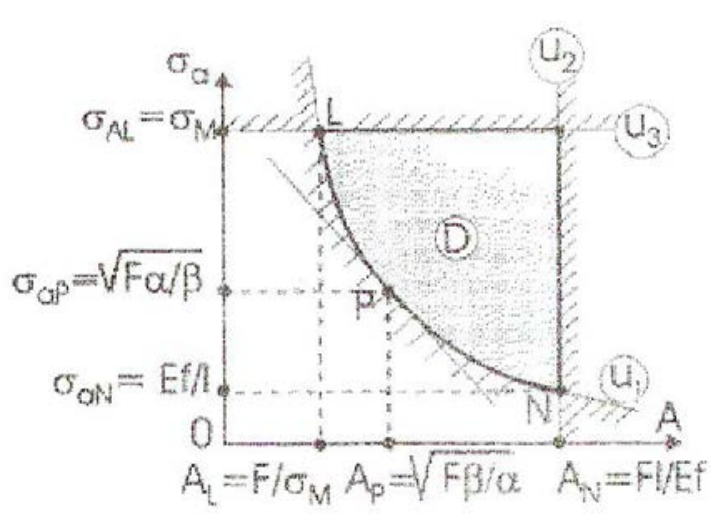

$\rightarrow$ Equation 1 is represented by $u_{1}$ hyperbole spring. The equation of this curve is $u_{1}=0$, $\sigma_{a}=\frac{F}{A}$ 
"Mircea cel Batran" Naval Academy Scientific Bulletin, Volume XX - 2017 - Issue 1

The journal is indexed in: PROQUEST / DOAJ / Crossref / EBSCOhost / INDEX COPERNICUS / DRJI / OAJI I

JOURNAL INDEX I I2OR / SCIENCE LIBRARY INDEX / Google Scholar / Academic Keys/ ROAD Open Access I Academic Resources / Scientific Indexing Services / SCIPIO / JIFACTOR

$\rightarrow$ Equation 2 is represented by a straight $u_{2}$, where $u_{2}=0, A=\frac{F \cdot l}{E \cdot \delta_{\max }}=$ const.

$\rightarrow$ Equation 3 or function is represented by the right. Her equation is $u_{3}=0$ or $\sigma_{a}=\sigma_{a M}$

$\rightarrow$ Field (D), comprised between these curves $\left(u_{1}, u_{2}, u_{3}\right)$ is the possible solutions. Any point in this area (coordinate $\left(A, \sigma_{a}\right)$ ) is a solution of problem

$\rightarrow \quad$ End function (corresponding equation), $\min (\mathrm{P})$ - the minimum price, written in the form

$$
\sigma_{a}=-\frac{\alpha \cdot A}{\beta}+\frac{P}{\beta}
$$

is a graphical representation of straight inclined family, approaching the home when the price drops.

Optimal solution of these straight tangent point $\mathrm{P}$ corresponds to one of these straight to the intersection with hyperbole $u_{1}$.

Coordinates of the point $P$ is obtained considering the angular coefficient of the straight line $m_{1}=-\frac{\alpha}{\beta} \quad$ (from equation (5)) and $m_{2}=\frac{d \sigma_{a}}{d A}=\frac{F}{A^{2}} \quad$ or $\quad-\frac{\alpha}{\beta}=-\frac{F}{A^{2}}, \quad$ and coordinates of $P$ are

$$
P\left[A_{P}=\sqrt{\frac{F \cdot \beta}{\alpha}} ; \sigma_{a P}=\frac{F}{A_{P}}=\frac{\sqrt{F \cdot \alpha}}{\beta}\right] .
$$

$\Rightarrow$ "L" point in the diagram corresponds to the minimum volume solution using the material with the highest resistance admitted $\sigma_{a M}$

$\Rightarrow$ "N" point of the diagram corresponds to the situation when using the material with the lowest resistance admitted

Optimal solution - is analyzed considering the following cases:

* When $\sigma_{a P}>\sigma_{a L}$, assures minimum price point $\mathrm{L}$

* When $\sigma_{a P}>\sigma_{a L}$, assures minimum price point $\mathrm{N}$

* When $\sigma_{a P} \in\left[\sigma_{a L} ; \sigma_{a P}\right]$, (if the figure), the minimum price corresponds point $\mathrm{P}$

For the solution to be compatible it is necessary that $\sigma_{a N} \leq \sigma_{a L}$ or $\frac{E \cdot \delta_{\text {min }}}{l} \leq \sigma_{a M}$

\section{Numerical example:}

$F=10^{7} N$ $l=150 \mathrm{~mm}$

$\delta_{\text {max }}=1 \mathrm{~mm} ; \alpha=0,5 ; \beta=0,02$;

$E=2,1 \cdot 10^{5} \mathrm{MPa} ; \sigma_{M}=660 \mathrm{MPa}$

- Classical method

Select a material with $\sigma_{a}=140 M P a$ it result $V_{C M}=\frac{F}{\sigma_{a}}=71428 \mathrm{~mm}^{2}$, and the cost price is $P_{C M}=385,14 l e i$

- Optimal solution

Select a material with $\sigma_{a}=500 M P a$ it result $V_{O P T}=\frac{F}{\sigma_{a}}=2000 \mathrm{~mm}^{2}$, and the cost price is $P_{\text {OPT }}=200$ lei

Compared analysis:

$\checkmark$ Classical method design indicates that the volume of material is 3,57 times higher then the optimal design

$$
\frac{V_{C M}}{V_{O P T}}=3,57
$$

$\checkmark \quad$ Classical method design indicates that the cost price is 1,92 times than the optimal design

$$
\frac{P_{C M}}{P_{O P T}}=1,92
$$


"Mircea cel Batran" Naval Academy Scientific Bulletin, Volume XX - 2017 - Issue 1

The journal is indexed in: PROQUEST / DOAJ / Crossref / EBSCOhost / INDEX COPERNICUS / DRJI / OAJI I

JOURNAL INDEX I I2OR / SCIENCE LIBRARY INDEX / Google Scholar / Academic Keys/ ROAD Open Access I Academic Resources / Scientific Indexing Services / SCIPIO / JIFACTOR

\section{Conclusions}

Using standard, result in a bar with a volume 3.57 times higher than the optimal design and a price 2 times higher.

For optimal design of external loads must be known and how they act on the part.

Relationships established in Strength of Materials voltages, design and checking turns restrictions (written form of inequality) and plot the equations (boundary).

It establishes a function of purpose (which must be maximum or minimum). Result on the chart, a range of possible solutions.

Curves (lines) that separates ensure compliance with all the restrictions imposed (stress, displacement, etc.). The verification process of the solutions is eliminated and the choice of materials is not arbitrary, but depends on the function of purpose (to be maximized or minimized).

The system of equations (inequalities) that represent the purpose and function restrictions, represents optimal model (operational) and it is deducted from an algorithm (method of calculation).

For each type of machine element can develop such operational models. If they are transposed into charts (as in Figure - bumper under full tension) and traces the family of curves for different material with different characteristics, they can be used directly in the computation of order no longer necessary checks.

\section{Bibliography}

[1] BUZDUGAN, Gh., Rezistența materialelor, Ed. Academiei, București, 1986

[2] BUZDUGAN, Gh., ș.a., Calculul de rezistență în construcția de mașini, Ed. Tehnică, București, 1979

[3] CHISIN, A., ș.a. Organe de mașini, Ed. Didactică și Pedagogică, București, 1981

[4] GAFIȚANU, M., ș.a., Organe de mașini. Ed. Tehnică, București, 1981-83

[5] JOHNSON, C.R., Optimum design of mechanical elements, New York, Ed. John Wiley Inc, 1961

[6] RĂDULESCU, O., Sinteze optimale în construcția de mașini, Ed. Tehnică, București, 1984

[7] RĂDULESCU, O., Organe de mașini. Sinteze optimale. Ed. Academiei Militare, București, 1982

[8] RĂDULESCU, O., ș.a., Proiectarea optimală a organelor de mașini, Ed. Tehnică, București, 2003 